\title{
Associated petroleum waters, as a promising source of lithium
}

\begin{abstract}
In this paper, we attempted to estimate the size of mineral resources that are poor in lithium content. Due to possible depletion of existing resources, poor resources can become the most promising source of resources. Possible directions and prospects f lithium extraction from poor sources of raw materials, which are underground waters, associated oil waters. The directions for solving these problems are continued. Nowadays, hydro-mineral raw materials gradually become the main source of lithium. In view of complexity of the salt composition of hydro-mineral raw materials, the use of highly selective inorganic ion-exchange materials is the most promising method for recovery of lithium.
\end{abstract}

Keywords: lithium, lithium resources, hydro-mineral raw materials, oil waters, extraction of lithium, inorganic, ion, exchange, materials, selective, lithium
Volume 3 Issue 4 - 2018

\section{Kudryavtsev P,' Kudryavtsev $\mathrm{N}^{2}$}

'Deputy Director for Research and Development, Israel

2Polymate Ltd Israel Nanotechnology Research Center, Israel

Correspondence: Kudryavtsev P, Professor, Deputy Director for Research and Development, Polymate Ltd-Israel Nanotechnology Research Center, POBox 73, Migdal HaEmek 23I000I, Israel, Tel +972 (52) 726-56-47, Fax 972 (4) 604-2I-75, Email pgkudi89@gmail.com

Received:September 18, 2018 | Published: October II, 2018

\section{Introduction}

\section{Assessment of world lithium reserves}

To date, lithium is a mineral resource, which is characterized by some of the fastest growth rates in terms of price, consumption and production volumes. In our paper, ${ }^{1}$ we attempted to estimate the rates of consumption, the growth of production volumes and the growth of the explored volumes of lithium mineral resources. The growth of lithium consumption stimulated the growth of geological exploration of its mineral resources, which resulted in a sharp increase in explored reserves. In paper ${ }^{1}$ it was shown that, in 2010-2012 there was a sharp jump in the size of world reserves of lithium. This jump was provided by countries such as Chile, Argentina and China. At the same time, world production of lithium is also growing. ${ }^{1}$ In our paper, ${ }^{2}$ we noted that the existing reserves are only $30 \%$ of the lithium volume in the underground brine and associated oil waters. Thus, it is possible to roughly estimate the prospected, but not approved, lithium reserves in these sources. Their value is about 50 million tons.

As it is known, underground brines and associated oil waters are formed because of dissolution of salt mineral deposits of saline sedimentary basins in the Earth's crust by water entering the Earth's interior from the surface. Accordingly, saline sedimentary basins are sedimentary rocks containing salt and mostly halogen strata, most often one or more halogen formations. Among the main sedimentary basins of the world, about half (more than 110) contain layers with halide salts, and they are sources of salt brines. ${ }^{1}$ Saline basins are widespread throughout the planet. They are installed within all continents, seas, oceanic outskirts, absent only on the abyssal spaces of the actual oceans, where they are "implanted" only in their nearcontinental parts. The position of the salt basins on the world map is shown in our work. ${ }^{1}$ on land and in the water; salts are opened to all the depths of the earth's interior currently available for drilling. They are also associated with extremely high concentrations and reserves of boron, lithium, sometimes potassium, and rubidium, etc. ${ }^{3}$ these deposits were periodically formed in the historical interval from 600 million $\mathrm{BC}$ and up to the present time.

In assessing the potential suitability of various salt deposits as potential lithium resources, it is of interest to evaluate the relationship of lithium content with the content of other elements in underground brines. In connection with the growing demand for the world market in lithium compounds, many companies in the world have begun drilling wells and sampling underground brines. Some of them publish data analysis of these solutions. For example, the company Portofino Resources Inc. published data on the composition of samples of underground brines extracted from 34 wells located in 3 districts:

a. Hombre Meurto West in Salar del Hombre Muerto, Argentina

b. Is located approximately $10 \mathrm{~km}$ from the Chile border, $27 \mathrm{~km}$ east of Wealth Minerals' Laguna Verde

c. The southern extension of the Rio Grande salar in Catamarca, Аргентина. ${ }^{4}$

They determined the content of lithium, potassium and magnesium in the samples studied. Analysis of the available data is presented in Figure 1.

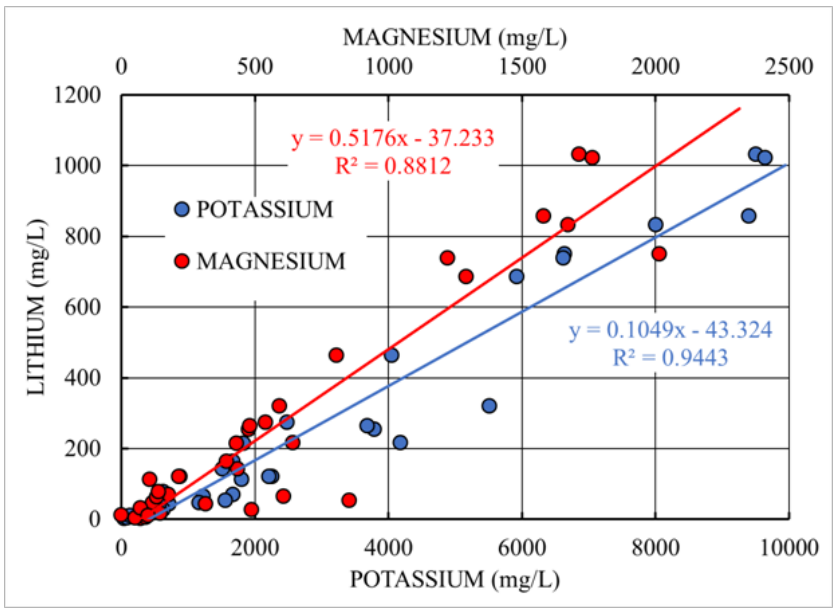

Figure I Correlation of lithium content in samples of underground brines, extracted by Portofino Resources Inc., with potassium and magnesium, as the main impurities in chloride brines. 
The data obtained show that the lithium content in the underground brines directly correlates with the content of potassium and magnesium. However, the correlation coefficient of lithium and potassium is $\mathrm{R}^{2}=0.9443$, which indicates that their correlation is almost perfect. At the same time, the correlation of lithium and magnesium is much worse and makes only $\mathrm{R}^{2}=0.8812$. This effect is because lithium and potassium are alkaline metals and have very similar, both chemical properties, and geochemical behavior, unlike magnesium, whose properties and behavior are closer to calcium and other alkaline earth metals than to alkali metals. Thus, the content of potassium in salt deposits can be an indicator of the presence of lithium there. These data are confirmed in other deposits of underground salts. ${ }^{4}$

The increased content of lithium is observed primarily in chloridesodium, chloride-and sulfate-potassium formations. The volumes of these formations have been determined quite accurately. ${ }^{4}$ To estimate global lithium resources, we use data on chloride-potassium salt reserves, since lithium tends to accumulate in such sediments. According to the data of, ${ }^{4}$ the volume of deposits of chloride-potassium salts is about 77 million $\mathrm{km}^{3}$. Considering the density of these salts, approximately equal to $2.1 \mathrm{~g} / \mathrm{cm}^{3}$, we obtain a mass of these deposits, which is about $1.6 \cdot 10^{17}$ tons. Since the content of lithium in such rocks is usually less than the total content of potassium and sodium by about $5500 \div 11000$ times, and the rocks are mainly chlorides. It is possible to estimate the approximate reserves of lithium in these rocks, which amount to about $7.4 \cdot 10^{12}$ tons of lithium. Hence it can be concluded that groundwater should contain a certain amount of lithium. In the underground solutions studied in the world, the content of lithium usually ranges from 1 to $200 \mathrm{~g} / \mathrm{m}^{3}$, depending on the place of extraction of the ground brine. Poor in lithium brines are solutions containing less than $100 \mathrm{~g} / \mathrm{m}^{3}$. Such brines are everywhere where the salt deposits are located. Since the groundwater poor in lithium is, in essence, inexhaustible and locally renewable as a source of lithium.

\section{Prospects for the development of lithium production in the world}

To date, the world's lithium production volume is 40 thousand tons of lithium per year. However, the forecasted growth in lithium production, the volume of its extraction by 2020 can reach $52^{\prime} 000 \div 65^{\prime} 000$ tons. Thus, the increase in production volumes can amount to $12 \div 25$ thousand tons of lithium per year. Taking for the reference the price for lithium carbonate for $\$ 13^{\prime} 400$ for 1 ton of lithium carbonate, we will get a possible increase in the volumes of the lithium market. This increase should be expected for $\div 1$ '750 million\$ per year. Taking into account that the prices for lithium carbonate in China, as already noted above, have more than doubled, compared to the base price, then the growth in the lithium market can double. Taking into account the increase in the price of lithium carbonate, this increase can amount to $\$ 1.5$ to $\$ 3.5$ billion per year.

This increase in the lithium market can be achieved in several ways. The first way is an extensive way, connected with the increase in the capacities of existing production facilities of operating enterprises and with the growth of lithium extraction from existing sources. However, this path is limited to existing and potential lithium reserves. Their reduction will lead to a gradual decrease in the rates of production growth due to depletion of resources. This effect has already occurred in fact with the extraction of lithium minerals, the share of which in existing reserves has tended to decrease over the past 20years (Figure 2).

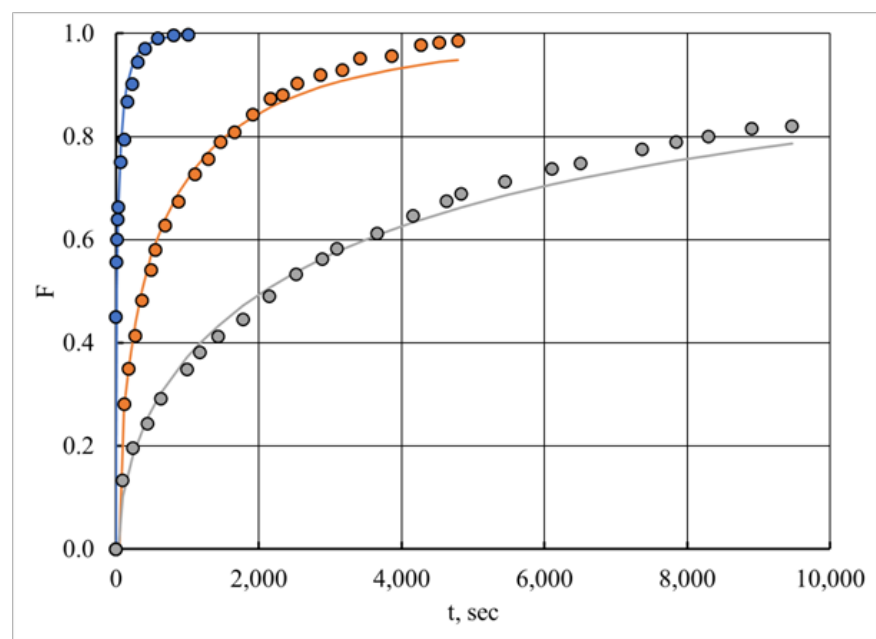

Figure 2 Kinetic curves of lithium sorption by cationite depending on the granule size.

The projected increase in lithium production can be provided in three ways:

Increasing the efficiency of lithium extraction from existing sources of raw materials

a. Attraction of poor lithium sources as resources, such as underground brines, associated petroleum waters and lake water with low lithium content.

b. Recycling of failed lithium batteries.

Speaking about increasing the efficiency of lithium extraction from existing sources of raw materials, we should pay attention to the following fact. The existing schemes for processing brines of lakes with high lithium content are based on a halurgical transformation. This technology allows extracting, on average, no more than $75 \%$ of lithium contained in the initial solution. Thus, $25 \%$ of lithium remains in the tailings of processing. Given that the average volume of lithium production is about 40 thousand tons of lithium per year, the volume of such losses is about 10,000 tons of lithium per year. Based on our basic price of lithium carbonate, we will get the volume of underreceived lithium carbon for $\div$ ' 500 million \$per year, depending on the possible price.

We will analyze the situation with associated oil waters. The problem of excluding the negative effect of intermediate water layers on the process of sludge of extracted oil concerns all the oil regions of the world. The average watercut of oil produced, according to the oilextracting industry of Russia, is more than $75 \%{ }^{5}$ since the volume of oil production in Russia is one of the largest in the world, this amount can be spread with certain probability to the entire oil produced in the world. Therefore, according to data for 2016, the world oil production is 4 ' 432.4 million tons per year. Hence, the volume of associated oil water produced together with oil is approximately 3300 million $\mathrm{m}^{3} /$ year. Usually, the lithium content in these waters varies between 5 and $50 \mathrm{~g} / \mathrm{m}^{3}$. For the estimated calculation, we take the value of lithium content $10 \mathrm{~g} / \mathrm{m}^{3}$. Hence, it is possible to determine the approximate potential volume of lithium, which can be extracted from associated petroleum waters. This volume is approximately 33,000 tons of lithium per year. Thus, approximately 176 thousand tons of lithium carbonate can be obtained. This value is equivalent to the volume of 
the lithium carbonate market from 2.4 to 5.3billion \$/year, depending on the price of lithium carbonate.

The problem of recycling lithium batteries should be considered as a promising task, which is complicated by the organizational problem of collecting used batteries. Historically, lithium recycling has been negligible, but it has been steadily increasing due to increased consumption of lithium batteries. One of the US companies has been processing lithium metals and lithium-ion batteries since 1992 at its facility in British Columbia, Canada. In 2009, the US Department of Energy allocated a grant of $\$ 9.5$ million to the company for the construction of the first lithium-ion battery storage facility. The construction was completed in 2015.

It is possible to estimate the potential volume of the secondary lithium market of their used batteries. As we noted earlier, $35 \%$ of the volume of lithium produced goes to the manufacture of lithium batteries. Since the volume of lithium production is about 40,000 tons per year, the amount of lithium consumed for the manufacture of batteries is approximately 14,000 tons per year. It can be assumed that all this volume of lithium is going to update the existing battery fleet. This assumption is not very far from the truth, since small batteries serve from one to two months, and the service life of large batteries does not exceed 3 years. Therefore, the obtained estimate gives an upper bound for estimating the volume of the lithium market for batteries. Hence, we have a market volume from \$1.0 to \$2.2 billion per year, depending on the price of lithium carbonate.

\section{Extraction of lithium using highly selective inorganic ion-exchange materials}

Prospective materials for the extraction of lithium and other rare and dispersed elements from natural solutions are highly selective inorganic ion-exchange materials. ${ }^{6}$ In various literature sources, inorganic ion exchangers are also called inorganic sorbents. Usually, in contrast to their organic analogs, Inorganic ion exchangers have rigid structures and do not undergo appreciable changes in the ion exchange process. A rigid structure leads to a certain and unusual selectivity. The selectivity of inorganic ion exchangers can be considered from the point of view of an ionic sieve effect, steric factors, an ionic size preference, an entropy effect and an ion memory effect. These materials, in comparison with conventional organic ion exchangers, are characterized by higher selectivity, radiation, and thermal and chemical stability. ${ }^{7,8}$

Among the currently known inorganic sorbents, low solubility oxygen compounds of various elements occupy a large place. Among them, a class of hydrated oxides of polyvalent metals is of a great theoretical interest and practical importance. Many of the works performed in Russia and in other countries devoted to the study of sorption properties of hydrated oxides have revealed their good ionexchange properties, and what is especially important is that these works for the first time showed that under the effect of various factors the structure and properties of hydrated oxides can be broadly modified. In other words, they have such a variety of structural types that allow them to be modified in a wide range, while creating ion-exchange materials highly selective to certain types of ions. Ion exchange on hydrated oxides proceeds with the participation of functional $\mathrm{OH}$ groups having sufficiently different acid-base properties. This allows one to consider them as a universal basis in the synthesis of ionexchange materials that have a certain set of properties.
A lithium ion is characterized by a small size $r_{i}=68 \mathrm{pm}$ and high hydration energy $\left(\Delta G_{\text {Hidr }}=-507 \mathrm{~kJ} / \mathrm{mol}\right)$. Accordingly, an ion exchanger, selective to lithium, must have a dense structure having micro-voids available for lithium ions $\mathrm{Li}^{+}$. A local distribution of the excess charge of the polyanionic framework should be favorable for singly charged exchange cations. The solvation energy of $\mathrm{Li}^{+}$ions in the solid phase should be sufficient to compensate for the energy expenditure for dehydration of $\mathrm{Li}^{+}$ions during their entry into the ionexchanger phase. In our works we considered some ways of synthesis of inorganic ion-exchangers based on metal oxyhydrates, ensuring fulfillment of these conditions. ${ }^{9-13}$

As the basis for the synthesis of ion exchangers, oxyhydrates can be chosen for metals $\mathrm{Nb}(\mathrm{V}), \mathrm{Mn}(\mathrm{IV}), \mathrm{Ti}(\mathrm{IV}), \mathrm{Sn}(\mathrm{IV}), \mathrm{Zr}(\mathrm{IV})$. Metals are located in the sequence of decrease in the values of the $z / r$ ratio (where $\mathrm{z}$ is the ion charge, and $\mathrm{r}$ is the ion radius). Based on the above, a corresponding decrease in their acid properties was observed in the following sequence: $\mathrm{Nb}>\mathrm{Mn}>\mathrm{Ti}>\mathrm{Sn}>\mathrm{Zr}$. Thus, hydrated oxides of niobium, manganese and titanium are the most suitable basis for the synthesis of cation exchangers selective to lithium. The experimental studies carried out have shown a decisive role of the structure of the solid phase for achieving specified ion-exchange families. The possibility for synthesizing ion-exchange materials based on hydrated oxides of manganese (IV), titanium (IV) and niobium (V) was also shown. ${ }^{9-13}$

The work on changing properties of ion exchangers based on hydrated metal oxides were aimed at providing them with selectivity, chemical and mechanical stability, and other properties. In this connection, V.V. Volkhin and other scientists of the Department of General and Inorganic Chemistry of the Perm Polytechnic Institute developed a method of thermal modification of ion-exchange materials. ${ }^{9-13}$ The application of this method to hydrated oxides of titanium and manganese (IV) allowed to obtain high results. Thus, cation exchangers selective to $\mathrm{Li}^{+9-14}$ and $\mathrm{Sr}^{2+15}$ were synthesized.

Kudryavtsev $^{2}$ and his colleagues developed and industrially tested methods for manufacturing a large range of inorganic ion-exchange materials, including lithium-selective materials. ${ }^{16-40}$ Experimental production of these sorbents was organized and tested on real natural objects. In particular, selective sorbents for lithium were tested in underground iodine-benign waters in the Perm Oblast of the Russian Federation and at associated oil waters of various deposits in the territory of the Russian Federation. As an example, we can refer to the results of tests of sorbents selective for lithium, the study was conducted for checking a possibility of lithium recovery from associated oil waters of Dagestan (in the region of South Sukhokumsk). The mixture of associated mineralized waters had the following composition $(\mathrm{g} / \mathrm{l})$ : $\mathrm{NaCl}$-75,5; KC1-15,8; $\mathrm{CaCl}_{2}-20,3 ; \mathrm{MgCl}_{2}-2,20 ; \mathrm{SrCl}_{2}-1,22 ; \mathrm{LiCl}-$ 0,52 . This solution also contained a certain amount of rubidium and cesium. Their extraction was also included in the general work plan. It was planned to carry out complex processing of these raw materials. Studies were discontinued in the early 90 's.

As already noted, the existing industrial schemes for complex processing of brines, including the preparation of lithium compounds, are oriented to rich sources (the content of lithium is $300-500 \mathrm{mg} / \mathrm{l}$ ) and is based mainly on evaporation with successive crystallization of various compounds. For the poor in rare elements of brines, the most promising are sorption methods. ${ }^{7,14}$ Effective isolation of lithium from solutions in the form of a carbonate is possible when its content 
in the solution is not less than $20-25 \mathrm{~g} / 1$, which for brines with a lithium content of $40 \mathrm{mg} / 1$ corresponds to a 500 -fold degree of concentration. In addition to the given degree of concentration, the developed ionexchange processes provide a desired productivity. The problem of lithium extraction from hydrochloric brines is largely related to the molar ratio of $\mathrm{Na}^{+}$and $\mathrm{Li}^{+}$ions in them, i.e. to the value of $\mathrm{Na} / \mathrm{Li}$. Sodium is one of the elements closest to lithium in terms of chemical properties and, in addition, as a rule, has the largest content in natural waters. In some classes of chloride brines, the $\mathrm{Na} / \mathrm{Li}$ ratio can reach $9.5 \cdot 10^{4}$. Under such conditions, conventional methods, which are based on the precipitation of sparingly soluble lithium compounds, for example phosphates, are not effective. Only sorbents highly selective to $L i^{+}$ions are promising.

Consider a qualitative description of the selectivity phenomena. When studying ion exchange, it was found that, although the exchange of ions usually occurs in stoichiometric quantities, the exchanging ions, as a rule, are retained by the ion exchanger unequally. So, if an ion exchanger in contact with a liquid phase containing in equivalent quantities of two exchangeable ions, and after establishing equilibrium between the solid phase of the ion exchange and the solution, the quantities of these ions in the ion exchanger phase, expressed in equivalents or moles, will not be equal. Thus, the ion exchanger "prefers" ions of a certain kind. This phenomenon is called selectivity or selectivity. Let us consider the equilibrium of an ion exchanger with two types of singly charged counterions (they are called so because their charge is opposite in sign to the charge of fixed ion groups of the ion exchanger). These counterions (denoted by A and $\mathrm{B}$ ) are present both in the ion exchanger and in the solution. We can write the ion exchange reaction

$$
\bar{A}+B \leftrightarrow A+\bar{B}
$$

The dash indicates that the ion is in the ion exchanger phase. Then the coefficient of selectivity, or the coefficient of relative affinity, is determined by the expression

$$
K A B \frac{\bar{X}_{B}}{\bar{X}_{A}} \frac{X_{A}}{X_{B}}=\frac{\bar{X}_{B}}{X_{B}} \frac{X_{A}}{\bar{X}_{A}}=\frac{K_{d}^{B}}{K_{d}^{A}}=\frac{\varepsilon_{B} C_{A}}{C_{B} \varepsilon_{A}}
$$

Where $\bar{X}_{A}$ and $\bar{X}_{B}$ equivalent fractions of counterions $\mathrm{A}$ and $\mathrm{B}$ in the ion exchanger phase, $X_{A}$ and $X_{B}$-equivalent fractions of the same ions in solution. It's obvious that $\bar{X}_{A}+\bar{X}_{B}=1 \& X_{A}+X_{B}=1$ . Parameters $K_{d}^{A}$ and $K_{d}^{B}$ are called the distribution coefficients of the corresponding ion between the liquid phase of the solution and the solid phase of the ion exchanger. If we move from dimensionless equivalent parts to dimensional quantities, we can introduce the following notation: $\varepsilon_{A}$ and $\varepsilon_{B}$ equilibrium values of the capacities of the ion exchanger to ions $\mathrm{A}$ and $\mathrm{B}$, expressed in units of [ $\mathrm{mol} / \mathrm{kg}]$. $C_{A}$ and $C_{B}$ according to the concentration of these ions in solution, expressed in molar units. Value of selectivity coefficient $K_{A B}$ defined by equation (1), quantifies the relative ionic composition of two phases-ion exchange and solution. Any value of $K_{A B}$ other than one is a measure of the relative difference in the affinity of these two phases to both competing ions. "Preference" for one ion compared to others in this phase is due to the relative influence of the two components on the thermodynamic properties of this phase. Thus, the selectivity coefficient is the main quantitative measure of the selectivity of a given ion exchanger to certain ions against the background of other ions.
Previous work has allowed the development of methods for the synthesis of several inorganic sorbents possessing high selectivity with respect to rare alkaline elements..$^{41}$ The sorbents ISMA- $1^{42}$ based on manganese and aluminum oxides are suitable for extraction of lithium and sorbents FS-2, FS-10 $0^{43}$ based on copper ferrocyanide are suitable for extracting rubidium and cesium. Ion exchange processes play an important role in chemical technology, hydrometallurgy and industrial ecology. ${ }^{44-46}$ Recently, more and more applications in ion-exchange technologies are found in inorganic ion exchangers. Unlike organic ion-exchange resins, inorganic ion exchangers have increased radiation and chemical stability, high selectivity, low cost. The possibility of effective use in technology of any ion exchangers not only by their equilibrium characteristics of capacitance and selectivity, but also by their sorption-kinetic properties. Organic ion exchangers have better kinetic properties than inorganic ones and are still broader in modern technology. The main reason for the insufficiently high kinetic properties of inorganic ion exchangers is often the slow diffusion of ions in crystallites. ${ }^{47,48}$ At the same time, it is precisely the features of ion exchange inside crystallites that largely explains the high selectivity of inorganic ion exchangers. However, by now the situation is improving. Created inorganic sorbents ${ }^{13,14}$ with a small size of crystalline blocks, which allowed to raise their operational properties to the required level.

Sorbent ISMA-1 is a weekly acidic cation exchanger, which ensures easy handling of lithium sorption on it. Desorption of the absorbed lithium is achieved by washing the saturated sorbent with a dilute solution of a strong acid, with most of the lithium being released in the neutral fraction of the eluate. The basis of sorbents is manganese dioxide. Due to thermal recrystallization, manganese dioxide acquires a structure in which the positions for the exchange cations strictly correspond to $\mathrm{Li}^{+}$ions, and the access of $\mathrm{Na}^{+}$ions to the inside of the crystalline grains is limited by the "ion-sieve" effect. During the processes of sorption and desorption, only the exchange of $\mathrm{H}^{+} \mathrm{E} \mathrm{i}{ }^{+}$occurs. The main characteristics of the ISM-1 sorbent are the following: separation coefficients for a pair of $\mathrm{Li}^{+}-\mathrm{Na}^{+}$ions reach $(1 \div 5) \cdot 10^{4}$, the exchange capacity is $4 \div 5 \mathrm{~mol} \mathrm{Li}^{+} / \mathrm{kg}$ (total) and $1.0 \div 2.0 \mathrm{~mol} \mathrm{Li}^{+} / \mathrm{kg}$.

This material is a highly selective sorbent with respect to lithium ions. Its sorption properties with respect to lithium ions make it possible to efficiently extract them from solutions with high mineralization, including from underground brines and associated petroleum waters. The specific selectivity of this cation exchanger to lithium ions is largely determined by the features of their crystal structure, and the exchange capacity - by the content and acidity of the $\mathrm{OH}$ groups. To investigate the effect of the diffusion of ions in pore space, the dependence of the sorption rate on the size of the granules. ${ }^{48-51}$ Experiments were performed with fractions of the cation exchanger obtained by sieving. Experimentally obtained curves for the case of lithium sorption from a solution with a lithium concentration of 0.001 $\mathrm{M}$ at $\mathrm{pH} 9.5$ and $25^{\circ} \mathrm{C}$ are shown in Figure 2.

The size of granules: 1-less than $0.088 \mathrm{~mm} ; 2-0.088-0.25 \mathrm{~mm}$; 3-0.25-0.5 mm.

As can be seen from Figure 2, with a decrease in the size of the granules, the rate of the ion exchange process increases substantially. Consequently, the kinetics of lithium ion exchange on a cation exchange with high selectivity to lithium ions is described by the diffusion equation 


$$
\frac{\partial \varphi(u)}{\partial T}=\frac{1}{R^{\mu}} \frac{\partial}{\partial R}\left(\delta(u) R^{\mu} \frac{\partial u}{\partial R}\right)
$$

Where $\varphi(u)$-dimensionless sorption isotherm; $u$ - the dimensionless concentration of ions in the transport pores of the granule; R-dimensionless coordinate (radius) inside the granule; $\delta(\mathrm{u})$ dimensionless coefficient of mutual diffusion; T-dimensionless time; $\mu$-granule shape index;

The initial and boundary conditions have the following form:

$$
\begin{aligned}
& \left.u(\mathrm{R}, \mathrm{T})\right|_{T=0}=0 \\
& \left.\frac{\partial u}{\partial R}\right|_{R}=0=0 \\
& \left.u(R, T)\right|_{R}=1=1
\end{aligned}
$$

Approximation of the experimental data (shown in solid lines in Figure 3) confirms that under the given conditions the process is actually controlled by internal diffusion. The index of the shape of the granule is $\mu=0.5$. The effective diffusion coefficients obtained for each of the fractions are close to each other and lie within the error of the experiment.

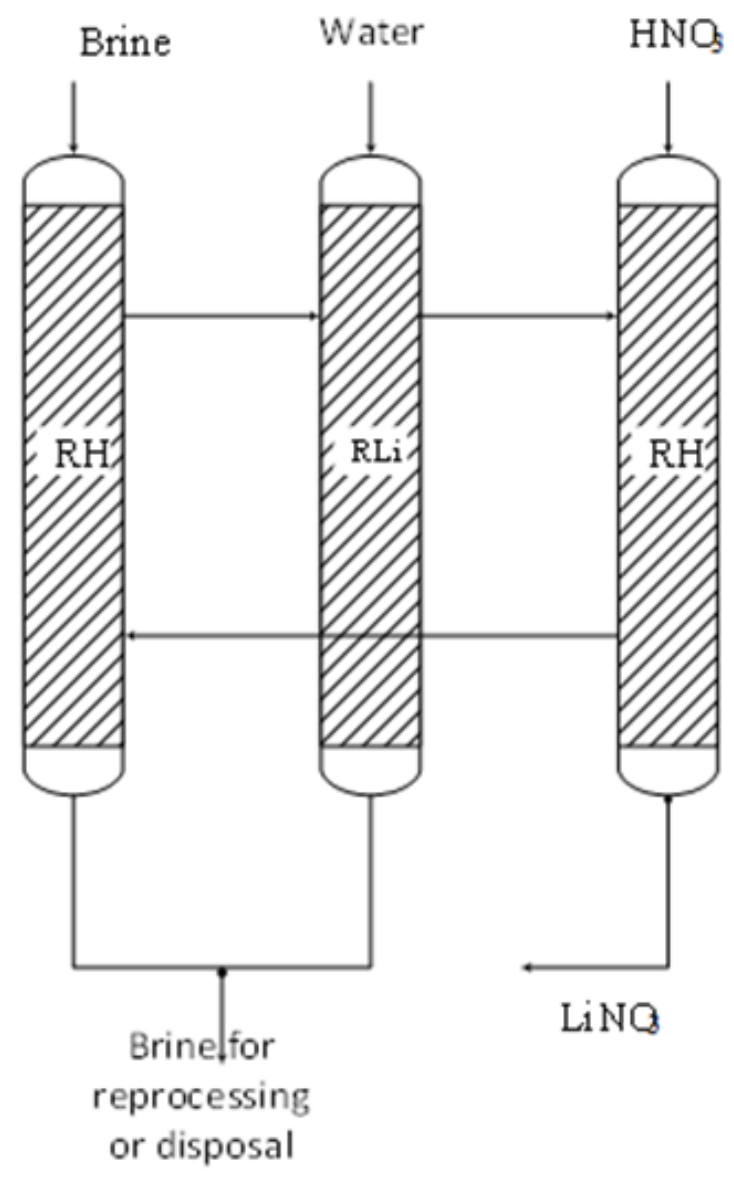

Figure 3 Three-column technological scheme of lithium recovery from hydromineral raw materials: $\mathrm{RH}$ cation exchanger in hydrogen form, initial state and state after lithium desorption; RLi is a cation exchanger in lithium form after absorption of lithium from the brine.
A modified ISMA-1 sorbent was tested in the process of lithium recovery from the underground solution of the iodine-bromine production (Perm, Russia) with the following composition: $\left(\mathrm{g} / \mathrm{dm}^{3}\right)$ : $\mathrm{NaCl}-189 ; \mathrm{CaCl}_{2}-56.05 ; \mathrm{MgCl}_{2}-14.9 ; \mathrm{KC} 1-2.47 ; \mathrm{NaBr}-1.12$; $\mathrm{SrCl}_{2}-0.42 ; \mathrm{Na}_{2} \mathrm{~B}_{4} \mathrm{O}_{7}-0.12 ; \mathrm{KI}-0.02 ; \mathrm{Li}^{+}-11 \cdot 10^{-3}, \mathrm{pH}-8.2$. Sorption was carried out before the leakage of $\mathrm{Li}^{+}$ions into the filtrate and reached a value of $0.9 \mathrm{mg} / \mathrm{dm}^{3}$. Test results: sorption capacity was $17 \mathrm{~g}$ $\mathrm{Li}^{+} / \mathrm{kg}$, lithium recovery was $91.5 \%$. A standard three-column process scheme was used in this test for lithium recovery from hydromineral raw materials. The first ion-exchange column received abrine for lithium recovery. The sorption process was carried out before the appearance of lithium in a leakage through the column. After that for removing residual rasp from the column, the column was switched to a washing with water. For desorbing the absorbed lithium, the washed column was then switched to treatment with a solution of nitric acid. The resulting lithium eluate was sent for further processing. After desorption of lithium, the column was again switched to pumping of the brine for extraction of lithium. In such a manner the process was cyclically repeated.

Reprocessing of a lithium eluate containing lithium in an amount of up to $4 \mathrm{~g} / 1$ includes the following steps:

\section{Precipitation of magnesium hydroxide:}

$$
\mathrm{Mg}\left(\mathrm{NO}_{3}\right)_{2}+\mathrm{Ca}(\mathrm{OH})_{2} \rightarrow \mathrm{Mg}(\mathrm{OH})_{2}+\mathrm{Ca}\left(\mathrm{NO}_{3}\right)_{2}
$$

Precipitation of calcium carbonate:

$$
\mathrm{Ca}\left(\mathrm{NO}_{3}\right)_{2}+\mathrm{K}_{2} \mathrm{CO}_{3} \rightarrow \mathrm{CaCO}_{3}+2 \mathrm{KNO}_{3}
$$

Next, the resulting solution is concentrated by evaporation to $10 \mathrm{~g} / \mathrm{l}$ in $\mathrm{Li}^{+}$, and lithium is precipitated as a carbonate. The obtained mother liquor is neutralized and evaporated for subsequent crystallization of potassium nitrate. After crystallization of potassium nitrate, the mother liquor is returned to the process for precipitation of lithium carbonate. Modeling processes in flowing ion-exchange columns is a very difficult task. Even for simple cases, the numerical solution of dynamics problems is not always possible, the more it is practically impossible to do analytically. In this case, the task is complicated by the specific shape of the sorption isotherm, which complicates the simulation even under steady-state conditions, as shown above. Another simplification applied in all nonequilibrium theories is the idealization of the hydrodynamic ratios in the ion-exchange layer, as well as the assumption of the spherical shape of the ion exchanger grains and their identical magnitude. Other difficulties arise because of the presence of temperature gradients that affect the thermal effect of ion exchange and violate local ion-exchange equilibria.

For such ideal cases, the differential equation of material balance can be written differentially. This equation takes the following form: $:^{52,53}$

$$
\vartheta \frac{\partial C_{B}}{\partial z}+(1-\beta) \frac{\partial \bar{X}_{B}}{\partial x}+\frac{\partial C_{B}}{\partial t}
$$

Where $\bar{X}_{B}$-the number of B ions in the ion exchanger per unit volume of the ion exchange; $\vartheta$-linear flow rate of solution in units of volume per unit cross section of the column per unit time; $\beta$-The volume of solution per unit volume of cation exchanger in the column. In any case, the solution of this equation will give only approximate 
solutions, therefore, in practice; it is most often resorted to conducting real tests on specific ion-exchange columns with an analysis of the composition of the incoming and outgoing stream. Based on these tests, suitable flow rates and ratios between the linear dimensions of the ion exchange columns. Such tests were carried out by us on pilot plants with different types of ion-exchange columns and on various types of natural solutions.

In conclusion, let us refer to some data, based on the results of laboratory studies and field trials, on the application of the described technique to processing of brines taken from the South Sukhokumsk field. The obtained experimental data is given in Table 1.

In general, the analysis of the proposed processes for extraction of lithium, rubidium, and cesium from hydromineral raw materials shows that the use of these processes provides obtaining of compounds of target and accompanying elements in the form of commodity products that meet the requirements of the existing technical conditions. The authors took an active part in developing methods for obtaining these and other similar sorbents, and in testing their properties on real industrial and natural solutions. ${ }^{7-13}$

Table I Rates of raw material consumption and output in terms of processing $1000 \mathrm{~m}^{3}$ of hydro-mineral raw materials

\begin{tabular}{llll}
\hline \multicolumn{2}{c}{ Consumption of raw material, kg } & \multicolumn{2}{l}{ Product output, kg } \\
\hline $\mathrm{HNO}_{3}$ & 577 & $\mathrm{Li}_{2} \mathrm{CO}_{3}$ & 137 \\
$\mathrm{~K}_{2} \mathrm{CO}_{3}$ & 520 & $\mathrm{Rb}_{2} \mathrm{NO}_{3}$ & 3,3 \\
$(\mathrm{NH} 2)_{2} \mathrm{CO}$ & 8 & $\mathrm{Cs} 2 \mathrm{NO}_{3}$ & 0,9 \\
$\mathrm{NaNO}_{2}$ & 19 & $\mathrm{Mg}(\mathrm{OH})_{2}$ & 53 \\
$\mathrm{CH}_{3} \mathrm{COOH}$ & 6 & $\mathrm{CaCO}_{3}$ & 155 \\
$\mathrm{CaO}$ & 52 & $\mathrm{KNO}_{3}$ & 684 \\
$\mathrm{KOH}$ & 48 & & \\
\hline
\end{tabular}

\section{Conclusion}

An analysis of the world's lithium resources and trends in lithium production and consumption showed that lithium resources and lithium production technologies currently in use have significant limitations. Given the existing rates of lithium production and consumption, the rich lithium resources can be depleted quickly enough, which in turn can lead to a sharp rise in lithium prices and, consequently, to a decrease in the profitability of its use in lithium batteries. At the same time, data on the general content of lithium in some rocks give very promising prospects for its mineral resources. An example of such lithium resources are underground brines and associated oil water. However, these resources are rather poor and modern high-tech methods are required to extract lithium from such sources. This method is the technology of lithium extraction using inorganic composite highly selective to lithium sorbents. Such sorbents were developed by us earlier. ${ }^{6}$ these sorbents can be used both for pre-extraction of lithium in existing plants and for the creation of new industries to extract their poor lithium natural solutions, such as groundwater and associated oil fields.

\section{Acknowledgements}

None.

\section{Conflict of interest}

The author declares that there is no conflict of interest.

\section{References}

1. Kudryavtsev P, Kudryavtsev N. Analysis of the world market of lithium. Resources, mining and development prospects. Journal Scientific IsraelTechnological Advantages. 2017;19(4):3-11.

2. Kudryavtsev PG. Lithium in Nature, Application, Methods of Extraction (Review). Journal Scientific Israel-Technological Advantages. 2016;18(3):63-83.

3. Belenitskaya GA. Tectonic aspects of the spatial and temporal distribution of saline basins of the world, Electronic scientific publication Almanac Space and Time. Special Issue System Planet Earth. 2013;4(5):1-31.

4. Belenitskaya GA. Saline sedimentary basins, Lithological-facies, geodynamic and mineralogical analysis Sedimentary basins of Russia. Russia: Publishing house VSEGEI; 2000;4:72.

5. Zaripov AG. Complex preparation of production of oil and gas producing wells. Moscow: Publishing house of the Moscow State Mining University; 2017. 199 p.

6. Kudryavtsev P. Alkoxides of chemical elements-Promising class of chemical compounds, which are raw materials for HI-TECH industries. Journal Scientific Israel-Technological Advantages. 2014;16(2):147-170.

7. Zilberman MV, Kalinin NF, Chentsova TV, et al. Sorption technology of processing natural brines into compounds of lithium, rubidium and cesium. Russia: Chemistry and technology of inorganic sorbents; 1989. $9 \mathrm{p}$.

8. Volkhin VV, Leontieva GV, Chirkova LG. Some principles of obtaining inorganic ion exchangers, selective to lithium ions, Inorganic ionexchange materials. In: Nikolsky BP. Leningrad: State University Press; 1980. $91 \mathrm{p}$.

9. Onorin SA, Volkhin VV. Method of obtaining inorganic ion exchangers. Patent USSR No. 455560. 1972.

10. Volkhin VV, Leontieva GV, Cheraneva LG, et al. The method of desorption of lithium from an inorganic ion exchange. Patent RF No. 811679. 1991.

11. Kudryavtsev PG, Onorin SA, Volkhin VV. A method for obtaining an inorganic sorbent for extracting lithium from solutions. A.S. USSR № 1160627.1983.

12. Kudryavtsev PG, Onorin SA, Volkhin VV, et al. Method for obtaining inorganic sorbent selective to lithium. Patent USSR No. 1256274. 1985.

13. Onorin SA, Volkhin VV. Composition for inorganic ion exchange. A.S. USSR No. 451456. 1972.

14. Senyavin MM, Krachak AN, Nikashina VA. Investigation of lithium sorption from highly mineralized solutions on various types of inorganic ion exchangers. Chemistry and technology of inorganic sorbents, Interuniversity collection of scientific papers. Russia: Perm; 1989:10-26.

15. Bengtsson GB, Bortun AI, Strelko VV. Strontium Binding Properties of Inorganic Adsorbents. Journal of Radioanalytical and Nuclear Chemistry. 1996;204(1):75-82

16. Kudryavtsev PG, Onorin SA, Volkhin VV. Inorganic ion exchanger $I S N-1$, selective to lithium ions. Izv. University: Non-ferrous metallurgy; 1977;3:50-53

17. Kudryavtsev PG, Onorin SA. Sorption of alkali metal ions by hydrated niobium pentoxide, Inorganic ion exchangers (synthesis, structure, properties). Brasil: Interuniversity collection of scientific works; 1997. p. $105-108$. 
18. Volkhin VV, Leonteva GV, Onorin SA, et al. Ionic-sieve cation exchangers for selective sorption of lithium, Chemistry and technology of inorganic sorbents. Russia: Perm; 1980. p. 67-71.

19. Kudryavtsev PG, Onorin SA, Volkhin VV. Method for the preparation of an inorganic anion exchanger. Patent USSR No. 1274763.

20. Kudryavtsev PG, Onorin SA, Volkhin VV. Choice of alloying ions and estimation of their influence on cation-exchange properties of oxyhydrate sorbents. Sverdlovsk: Solid State Chemistry; 1983. p. 67-75.

21. Kudryavtsev PG, Onorin SA, Volkhin VV. A method for obtaining an inorganic sorbent for extracting lithium from solutions. Patent USSR No.1160627.

22. Kudryavtsev PG, Onorin SA, Volkhin VV. A method of obtaining a lithium selective inorganic sorbent. Patent USSR No. 1203739. 1984.

23. Kudryavtsev PG, Onorin SA, Volkhin VV. Method for the preparation of an inorganic anion exchanger. Patent USSR No. 1125043. 1983.

24. Kudryavtsev PG, Onorin SA, Volkhin VV. Method for obtaining inorganic sorbent selective to lithium. Patent USSR No. 1256274.

25. Kudryavtsev PG, Onorin SA, Volkhin VV. Method for the preparation of an inorganic anion exchanger. Patent USSR No. 1189497.

26. Kudryavtsev PG. The equilibrium of ion exchange on oxyhydrate sorbents, complicated by the dispersion of exchange centers with respect to the exchange constant. Journal of Physical Chemistry. 1987;61(3):848-851.

27. Kudryavtsev PG, Onorin SA. Method for the preparation of inorganic anion exchanger AAT-1. Patent USSR № 1435280.

28. Kudryavtsev PG, Onorin SA, Volkhin VV. Method for the preparation of an inorganic anion exchanger. Patent USSR No. 1435281.

29. Kudryavtsev PG, Onorin SA, Volkhin VV. Synthesis and properties of selective lithium cation exchangers based on hydrated niobium pentoxide with alloying additives, Chemistry and technology of inorganic sorbents, Interuniversity collection of scientific papers. UK: Perm; 1989. p. 140149.

30. Kudryavtsev PG, Onorin SA, Volkhin VV. Influence of heat treatment on ion-exchange properties and structure of materials containing hydrated alumina, Izvestiya VUZ. Non-ferrous metallurgy. 1990;3(1):26-31.

31. Kudryavtsev PG, Volhin VV. Sol-gel processes and some of its technological applications, Sol-gel processes for obtaining inorganic materials. Bull. Mater Sci. 1991;15(5):421-430.

32. Kudryavtsev PG, Onorin SA, Volkhin VV. Structurization and ionexchange properties of mixed oxides in the $\mathrm{Li}_{2} \mathrm{O}-\mathrm{Fe}_{2} \mathrm{O}_{3}-\mathrm{Nb}_{2} \mathrm{O}_{5}$ system, Izvestiya AN SSSR, Ser. Inorganic materials. 1991;27(7):1479-1482.

33. Volkhin VV, Leonteva GV, Onorin SA. Synthesis, structure, properties of the ion-exchange cation exchanger ISM-1. AN SSSR. Inorganic materials. 1973;9(6):1041-1046.

34. Zilberman MV, Volkhin VV. The structure of mixed ferrocyanide copper and its corresponding products of molecular sorption. J. structural chemistry. 1971;12(2):649-652.

35. Leontieva GV, Chirkova LG, Volkhin VV. Thermal modification of manganese dioxide as a sorbent for alkaline-earth metal ions. Journal of Applied Chemistry. 1980;6(2):1229-1233.
36. Volkhin VV, Onorin SA. Sorption properties of hydrated titanium dioxide and its dehydration products. Izv AN SSSR. Inorganic materials. 1976;12(8):1415-1418.

37. Kalyuzhny AV, Volkhin VV, Zilberman MV, et al. Redox potential of mixed ferrocyanide cadmium and potassium. Journal of Applied Chemistry. 1977;50(1):201-203.

38. Kalyuzhny AB, Volkhin VV, Milyutin VV. Ferrocyanide electronion exchangers for the sorption of rubidium and cesium. Non-ferrous metallurgy: Izvestiya VUZ; 1980. 157 p.

39. Kalinin NF, Volkhin VV, Zilberman MV. Exchange and non-exchange sorption by poorly soluble inorganic compounds. Journal of Applied Chemistry. 1979. p. 524-528.

40. Onorin SA, Volkhin VV, Zilberman MB, et al. Synthesis of cation exchangers ISM-1A and IST-1A with increased exchange capacity. Izv. AN SSSR. Inorgan. Materials. 1978;14(1):150-153.

41. Volkhin VV. Selective inorganic sorbents and their use. Interuniversity. Chemistry and technology of inorganic sorbents. Perm; 1980. 19 p.

42. Leontieva GV, Volkhin VV, Chirkova LG, et al. Inorganic ion exchanger based on a mixture of manganese and aluminum oxides and the method of its production. $1980.34 \mathrm{p}$.

43. Kozlova GA, Volkhin VV, Zilberman MV. Method for the preparation of composite ferrocyanide sorbents. 1981.

44. Catamarca, Argentina Lithium. Argentina. 2018.

45. Kokotov Yu A, Pasechnik VA. Equilibrium and kinetics of ion exchange. London: Chemistry; 1970. 336 p.

46. Ionites in chemical technology. In: Nikolsky BP, Romankova PG. London: Chemistry; 1982. 416 p.

47. Chitrakar R, Kanoh H, Miyai Y, et al. Recovery of lithium from seawater using manganese oxide adsorbent $\left(\mathrm{H}_{1.6} \mathrm{Mn}_{1.6} \mathrm{O}_{4}\right)$ derived from $\mathrm{Li}_{1.6} \mathrm{Mn}_{1.6} \mathrm{O}_{4}$. Ind. Eng. Chem. Res. 2000;40(9):2054-2058.

48. Keay J, Wild A. The kinetics of cation exchange in vermiculite. Soil Science. 1961;92(1):54-60.

49. Volkhin VV, Pogodina OA, Leonteva GV. Nonstoichiometric Compounds Based on Manganese(III, IV) Oxides with the Birnessite Structure. Russian Journal of General Chemistry.2002;72(2);173-177.

50. Yang X, Kanoh H, Tang W, et al. Synthesis of $\mathrm{Li}_{1.33} \mathrm{Mn}_{1.67} \mathrm{O}_{4}$ spinels with different morphologies and their ion adsorptivities after delithiation. $J$. Mater. Chem. 2000;10:1903.

51. Saenko EV, Kolyshkin AS, Volkhin VV. Dynamics of three-component exchange on a cationite with lithium manganese spinel structure. Russ. J. Phys. Chem. 2007;81(2):255-258.

52. Helferich F. Ionites (fundamentals of ion exchange). M: Foreign Literature Publishing House; 1962. 492 p.

53. Venetsianov EV, Rubinstein RN. Dynamics of sorption from liquid media. Chemical Engineering Science. 1983;43(6):1323-1337. 